\title{
Quatro notas sobre as classes sociais nos dez anos do lulismo'
}

\author{
André Singer* \\ Universidade de São Paulo, Faculdade de Filosofia Letras e Ciências Humanas, Departamento de Ciência Política. São Paulo, SP, Brasil
}

Resumo: $\mathrm{O}$ artigo pretende contribuir para a formulação de hipóteses explicativas sobre algumas das mudanças na estrutura de classes ocorridas durante a década lulista (2003-2013). A melhora nas condições de vida por parte de cerca de 40 milhões de brasileiros acarretou uma reconfiguração em diversos pontos da sociedade. Desde o alívio na condição de sobrevivência do subproletariado, até o surgimento de uma pequena nova classe média, passando pela emergência de um vasto subproletariado, uma variedade de transformações atingiu, sobretudo, as camadas populares. $\mathrm{O}$ artigo busca apresentar interpretações iniciais a respeito destes diversos fenômenos.

Palavras-chave: classes, lulismo, ascensão social.

Retomo aqui algumas ideias expostas antes (Singer, 2012), tentando, a partir delas, dar alguns passos à frente, ainda que titubeantes. Assim, o que se lerá a seguir são notas que usam metodologia eclética em busca de formular hipóteses sobre o problema das mudanças na estrutura e nas coalizões de classe ocorridas durante a década lulista (2003-2013). O aspecto fragmentado da exposição trai a esperança de que com o tempo e as críticas se conforme um arranjo mais consistente para as ideias aqui expostas. Utilizo dados, instrumentos conceituais e intuições variados, ainda sem unidade, sujeitos, portanto, à revisão e à reinterpretação. Organizado na forma de quatro notas, o texto procura dar conta das questões que elenco a seguir.

Nos últimos dez anos houve um processo de ascensão social no Brasil, o qual mexeu positivamente com cerca de 40 milhões de pessoas. Isso gerou um debate sobre o possível surgimento de uma nova classe média no país. Em $O s$ sentidos do lulismo (A. Singer, 2012) sugeri que não era uma nova classe média que surgia, mas sim um novo proletariado (p. 212), que viria migrando do subproletariado, por exemplo, para a carteira assinada, o que lhe daria uma "cidadania trabalhista" que o proletariado propriamente dito tem desde os anos 1940. Um dos aspectos que desejo ressaltar é que apesar da referida migração ter se confirmado, o subproletariado continua a ser uma realidade importante no país. ${ }^{1}$

Não há dúvida que se está combatendo a pobreza e a desigualdade, mas de maneira lenta. Um estudo do economista Serguei S. Dillon Soares, do IPEA, mostra que o ritmo de queda do índice de Gini é compatível com os melhores momentos da construção do welfare state na Inglaterra e nos Estados Unidos (Soares, 2010), só que

1 Este artigo, escrito em novembro de 2013, nasceu na forma de uma conferência pronunciada para a Fundação Perseu Abramo e para a Fundação Friedrich Ebert em 02/05/2013. Agradeço o convite de Joaquim Soriano e Jean Tible para realizá-la. Com os acontecimentos de junho, fui obrigado a refazer partes inteiras, de modo que o roteiro original ficou bem modificado, mantendo, contudo, certa informalidade típica da exposição oral.

* Autor correspondente: avsinger@usp.br nosso patamar de partida foi muito pior que o desses países. Quando a Inglaterra e os EUA fizeram a forte redução da desigualdade, por volta dos anos 1930, partiram de um Gini que girava em torno de 0,40 , e nós, setenta anos depois, partimos de um Gini de 0,60 . Eis aí uma boa expressão do atraso brasileiro.

Embora o Gini nacional venha caindo de maneira regular, ${ }^{2}$ nesse passo levaremos mais uma geração para chegar à situação da Espanha pré-crise de 2008. Além disso, em função da diminuição do crescimento econômico no governo Dilma Rousseff, é possível que não se consiga manter o andamento anterior. A força que terá a redução da desigualdade daqui para frente dependerá de importantes decisões relativas ao próximo mandato presidencial. Seja como for, o subproletariado continuará a existir por muito tempo, o que, paradoxalmente, garante a permanência de uma base lulista.

O segundo aspecto que desejo indicar é a significativa participação que o novo proletariado parece ter tido nos protestos de junho de 2013, embora fossem manifestações predominantemente de classe média. A presença do novo proletariado nas demonstrações confirma a hipótese de que politização tende a acompanhar a ascensão social. No entanto, é um erro imaginar, e a ambiguidade dos protestos o mostraram, que tal politização se dará necessariamente à esquerda. Na realidade, o novo proletariado tanto pode caminhar para a esquerda, posição mais próxima de seus interesses objetivos, quanto para a direita, que oferece uma perspectiva de mercado para os setores que vem subindo. Mais ainda, penso que um centro pós-materialista pode também representar opção aceitável para tal setor, embora não seja óbvia a maneira pela qual tal conexão viria a ocorrer. ${ }^{3}$

2 Dados da PNAD 2012, divulgados em meados de 2013, mostraram, entretanto, uma interrupção do movimento de queda pela primeira vez em uma década. No entanto, ainda não está claro se isso representa uma nova tendência.

3 A respeito desse assunto ver A. Singer (2013). 
Em terceiro lugar, é preciso reconhecer a possibilidade do surgimento de uma pequena nova classe média, composta dos que deram um passo a mais no movimento ascensional, como se tivessem subido dois degraus em lugar de um. Para tal camada, os apelos do centro e da direita fazem mais sentido do que os da esquerda, embora não se possa descartar que parte dela se incline para valores progressistas, como, aliás, ocorre no seio da própria classe média tradicional.

Por fim, quero indicar mudanças recentes nas coalizões de classe, com um aparente rombo na coalizão produtivista. Durante o mandato de Dilma Rousseff ocorreram dois movimentos opostos, ambos de grande significado e ainda à espera de adequada compreensão. Em um primeiro momento, aprofundou-se o esquema de aliança de classes desenhado nos dois mandatos de Lula. Em maio de 2011, a tradicional Federação das Indústrias do Estado de São Paulo (Fiesp) assinou um programa comum com as centrais sindicais, formalizando o que eu vinha chamando de coalizão produtivista. Em seguida, a presidente colocou em prática a plataforma resultante do acordo. Porém, o efeito econômico foi frustrante. Em lugar de alavancar o crescimento, que vinha em declínio, este definhou em 2012. Diante do fracasso, o governo começou a recuar em 2013, não impedindo com isso, entretanto, o que parece ser uma reunificação da burguesia em torno da coalizão rentista.

\section{Nota 1. Permanência do subproletariado}

Há três indícios, todos eles apenas presumíveis, de que o subproletariado continua a englobar parcela expressiva da população brasileira. O primeiro é a quantidade de pessoas que ainda depende do Bolsa Família. A melhora na qualidade de vida propiciada pelas políticas do lulismo não tira, por si só, a pessoa da condição subproletária. Pode representar um alívio na pobreza, mas sem superá-la. O governo Dilma decidiu colocar como limite, para identificar a pobreza extrema, R\$ 70 per capita por mês. O que significa que, do ponto de vista oficial, qualquer pessoa que receber um pouco mais de $\mathrm{R} \$ 2,30$ por dia saiu da pobreza extrema. Com o programa Brasil Carinhoso, Dilma promoveu uma expansão do valor do auxílio e da cobertura do Bolsa Família (BF). Com isso, a partir de março de 2013 o governo garante que todos os beneficiários do $\mathrm{BF}$ recebem no mínimo $\mathrm{R} \$ 70$ per capita por mês, ficando, portanto, acima da pobreza extrema.

A própria dimensão e a importância que $\mathrm{o} \mathrm{BF}$ alcançou mostra o tamanho da camada que vive com baixíssima renda no Brasil. Ao completar dez anos, em setembro de 2013, o BF atendia cerca de 50 milhões de pessoas. ${ }^{4}$ Tratase de um quarto da população brasileira, ${ }^{5}$ que vive com

4 "Bolsa Família completa dez anos com 13,8 milhões de famílias beneficiárias". Disponível em http://www.casacivil.gov.br/central-de-conteudos/noticias/2013/10/bolsa-familia-completa-10-anos-com-13-8-milhoes-de-familias-beneficiarias.

5 Segundo divulgou o IBGE em 2013, a população brasileira é de 201 milhões de habitantes. uma renda aquém daquela que permitiria a reprodução de sua força de trabalho em condições "normais".

Para ilustrar o quanto o BF é indispensável para seus beneficiários, cabe lembrar o que ocorreu no fim de semana de 18 e 19 de maio de 2013, quando se espalhou o boato de que o programa iria acabar. Em questão de horas, centenas de milhares de pessoas em 13 Estados da federação, quase todos do Norte e do Nordeste, ${ }^{7}$ correram para caixas eletrônicos, que registraram quase um milhão de saques, além de depredações onde não foi possível retirar o dinheiro.

Um segundo elemento diz respeito à quantidade de trabalhadores que ainda recebem baixos salários no país. Cruzando dados sobre ocupação e remuneração, o economista Paul Singer estimava, com base na PNAD de 1976, que o subproletariado - composto dos que "oferecem sua força de trabalho no mercado sem encontrar quem esteja disposto a adquiri-la por um preço que assegure sua reprodução em condições normais" [P. Singer, 1981, p. 22]) representava $50 \%$ da População Economicamente Ativa (PEA). A categoria incluía todos os que tinham renda per capita de até um salário mínimo (SM) e a metade dos assalariados não agrícolas que tinham renda per capita entre um e dois salários mínimos.

Aplicando o mesmo critério para a PNAD de 2012, temos 24 milhões de trabalhadores, algo como $26 \%$ dos 93,5 milhões que compõem a PEA, recebendo até um SM. Acrescidos de metade de todos os que recebem entre um e dois salários mínimos, somando $24 \%$, a proporção de subproletários chegaria a $38 \%$ da força de trabalho. ${ }^{8}$ A PNAD 2012 revela ainda que $43 \%$ das famílias brasileiras apresentavam renda média mensal domiciliar per capita de um salário mínimo, o que representa 27 milhões de domicílios e algo em torno de metade da população.

É claro que nenhuma afirmação rigorosa pode ser feita a partir dos dados acima. O que tenciono indicar é tão somente a permanência, também no plano da renda, de elementos que permitem supor expressivo contingente subproletário passados dez anos de lulismo.

$\mathrm{O}$ terceiro número que quero destacar diz respeito à quantidade de trabalhadores ainda sem carteira assinada no Brasil, ou seja, que não têm acesso à proteção trabalhista, aos sindicatos e ao instrumento da greve, ficando assim à margem das conquistas que caracterizam a fração organizada da classe trabalhadora. O Quadro 1 mostra que, em 2009, 20\% dos empregados continuavam sem carteira

6 Convém lembrar que, além disso, existem cerca de 2,5 milhões de pessoas muito pobres que o governo não havia ainda conseguido cadastrar no Bolsa Família.

7 A única exceção foi o Rio de Janeiro.

8 Sobre esse assunto ver as reportagens: "IBGE: cresce volume de trabalhadores que ganham menos de um salário", disponível em http:// oglobo.globo.com/economia/ibge-cresce-volume-de-trabalhadoresque-ganham-menos-de-um-salario-1-10176438; e "Quase um quarto da população sem renda na RMF", disponível em http://diariodonordeste. globo.com.br/materia.asp?codigo=1322485. Não estão excluídos aqui os trabalhadores agrícolas, como fez Paul Singer (1981). 
de trabalho. Se somarmos a esses uma parte significativa dos trabalhadores domésticos, que ainda trabalha na informalidade, e outra parte dos chamados trabalhadores "por conta própria", parcela dos quais são apenas trabalhadores informais, veremos que uma proporção razoável do proletariado carece de cidadania trabalhista.

\section{Tabela 1}

Estrutura da ocupação das pessoas de 10 anos ou mais no Brasil, 2009

\begin{tabular}{lc}
\hline Ocupação & \\
\hline Porcentagem/Empregados com carteira assinada & $39 \%$ \\
Empregados sem carteira assinada & $20 \%$ \\
Trabalhadores domésticos & $8 \%$ \\
Trabalhador por conta própria & $21 \%$ \\
Empregadores & $4 \%$ \\
Trabalhadores não remunerados & $5 \%$ \\
Trabalhadores na produção para consumo próprio & $5 \%$ \\
Trabalhadores na construção para uso próprio & $0,1 \%$ \\
\hline
\end{tabular}

Fonte: Dieese, Anuário dos trabalhadores, 2010-2011. Reelaborado pelo autor. Valores arredondados, perfazendo mais de $100 \%$

Embora o governo tenha se empenhado, com resultados positivos, em aumentar a formalização do trabalho doméstico, sabe-se que boa parte dos milhões que vivem dessa atividade continua à margem da CLT. O mesmo se aplica ao trabalhador por conta própria, que pode ser desde o peão que faz bicos em obras avulsas até o microempresário. É verdade, também, que o lulismo criou mais de 17 milhões de postos com carteira de trabalho assinada, porém, não se pode esquecer que todo ano milhões de jovens chegam ao mercado de trabalho, exigindo uma forte expansão do número de postos formais somente para manter o quadro como está. Significativamente, a proporção de empregados com carteira assinada não passava de $40 \% \mathrm{em}$ 2009.

Em resumo, os três elementos apresentados que apontam na direção da permanência do subproletariado são: 1) em 2013, cerca de 25\% da população necessitava, de maneira imperiosa, do BF; 2) em 2012, 38\% da PEA tinha renda compatível com a condição subproletária, usando critério aproximado ao dos anos 1970; e 3) em 2009, ao menos $20 \%$ trabalhavam sem carteira assinada, acompanhados de $21 \%$ de trabalhadores por conta própria e $8 \%$ de trabalhadores domésticos, boa parte dos quais devem ser incorporados ao universo dos que carecem de cidadania trabalhista. Assim, o subproletariado, como fração específica dentro do proletariado, parece ainda pesar na formação social brasileira.

\section{Nota 2. Novo proletariado em movimento}

A vasta parcela de trabalhadores que estão aquém da condição proletária propriamente dita marca a formação social do país e produz o paradoxo de que o proletariado propriamente dito ocupa uma posição intermediária no Brasil, o que pode levar, em uma visão equivocada, a confundi-lo com a classe média. De fato, ele é uma fração de classe intermediária, porque sob ela há outra camada, mas isso não o caracteriza como classe média. Por outro lado, se, na formulação clássica de Marx, o proletariado não tem nada a perder, aqui ele sempre teve o que perder. O proletariado pode cair no subproletariado quando há desemprego, assim como pode sair dele quando o emprego aumenta.

O novo proletariado - os jovens e jovens adultos que entraram no mercado de trabalho na última década seria um grupo em transição, que está chegando agora à condição proletária. Ele tanto pode se fundir com o setor organizado da classe trabalhadora - o velho proletariado -, quanto desviar-se dele, partindo para formas próprias de comportamento político.

Tenho usado como parâmetro para pensar o novo proletariado o telemarketing, que foi pesquisado pelos sociólogos Ricardo Antunes e Ruy Braga (2009). O telemarketing, que empregava 1,4 milhão de pessoas em 2012, é interessante para pensar o novo proletariado porque recruta jovens para o primeiro emprego. Em geral, esses jovens têm ensino médio (ou superior) e salários baixos. ${ }^{9}$

Apesar do jovem operador estar com um pé fora do subproletariado, uma vez que pelo menos tem a carteira assinada, suas condições de trabalho são chocantes. Por exemplo: como precisam falar o tempo todo, ingerem grande quantidade de água, mas são impedidos de ir ao banheiro. A expectativa era que esses trabalhadores, uma vez tendo acesso ao sindicato, começassem a reivindicar melhorias e direitos.

Mas qual seria a postura dos sindicatos e partidos em relação a eles? Como estamos em face de um movimento sindical que também sofreu transformações, já não sendo o da década democrática (1978-1988), cabe perguntar se haverá verdadeiro interesse em dar guarida à potencial revolta do novo proletariado. De outra parte, no passado, o PT generalizaria a experiência dessa geração na forma de um programa político de enfrentamento do capital. Porém, essa não é a perspectiva do lulismo. Por isso, a possível experiência espontânea de politização do novo proletariado talvez não encontre correspondência no plano da luta sindical e partidária, levando a outro tipo de engajamento.

De acordo com algumas análises, a experiência espontânea das greves que vêm acontecendo no telemarketing, assim como nos canteiros de obras das hidrelétricas em construção e nos estádios da Copa, teriam sido precursoras da participação do novo proletariado nos acontecimentos de junho de 2013 (Braga, 2013). ${ }^{10}$ Não tenho como

9 Ver: "Telemarketing emprega 1,4 milhão no país; veja como é o trabalho no setor", disponível em http://g1.globo.com/concursos-e-emprego/noticia/2012/10/telemarketing-emprega-14-milhao-no-pais-veja-como-e-otrabalho-no-setor.html. O salário médio de um operador era de $\mathrm{R} \$ 706$, $14 \%$ maior do que o mínimo da época, mas mesmo assim baixo.

10 Braga prefere falar em precariado, enquanto eu adoto a expressão novo proletariado. Para o que vem ao caso aqui, a divergência é menor. 
aferir tal afirmação, mas olhando os dados a respeito de junho com atenção, pode-se deduzir a presença do novo proletariado nas ruas. ${ }^{11}$

Em primeiro lugar, as manifestações foram de jovens (até 25 anos) e jovens adultos (até 39 anos), que juntos representavam $80 \%$ dos presentes. À primeira vista, pareciam jovens de classe média, pois somando os diplomados aos que estavam cursando universidade, tinha-se um vasto contingente (quase $80 \%$ ) das manifestações de São Paulo em 17 e 20 de junho, assim como a de Belo Horizonte no dia 22 (quase $70 \%$ ), de manifestantes com acesso ao ensino superior. Se lembrarmos que, segundo o Ministério da Educação, em 2011 apenas 15\% dos jovens brasileiros estavam matriculados em universidades, mesmo que o número de ingressantes tenha se duplicado em uma década (Weber, 2012), pode-se supor que apenas a elite se engajou nos protestos.

Também o alto volume (92\%) dos que tinham pelo menos o curso médio completo nas oito capitais pesquisadas pelo Ibope e no Rio de Janeiro (86\%), praças para as quais não dispus da quantidade isolada de universitários, confirma que o nível educacional apurado naquelas ocasiões aponta para a metade superior da sociedade, com um perfil, no mínimo, de classe média baixa (ensino médio) (Souza \& Lamounier, 2010), mas com fortes tintas de classe média tradicional (universidade). ${ }^{12}$

No entanto, a renda revela um cenário diferente (Quadro 2). Os que tinham até cinco salários mínimos familiares mensais, que estão dentro do que se pode considerar baixo rendimento no Brasil, no conjunto respondiam por cerca de $50 \%$ dos manifestantes. Em outras palavras, uma parte substantiva estava na metade inferior da distribuição de renda, criando um contraste em relação à imagem que havia sido sugerida pela escolaridade, dimensão na qual a quase totalidade dos manifestantes encontrava-se na metade superior.

11 Os próximos parágrafos seguem de perto A. Singer (2013).

$12 \mathrm{O}$ conjunto de dados que analisei foi o seguinte: duas pesquisas realizadas pelo Datafolha em São Paulo, nas manifestações dos dias 17 de junho (766 entrevistas, com margem de erro de quatro pontos percentuais para mais e para menos) e 20 de junho (551 entrevistas, com margem de erro de quatro pontos percentuais para mais ou para menos). A primeira foi consultada em <www.datafolha.com.br> em 22/09/2014; a segunda foi consultada na Folha de S.Paulo, 22/06/2013, p. C6; pesquisa realizada na manifestação do Rio de Janeiro no dia 20 de junho pela Plus Marketing, com 498 entrevistas entre 16h e $20 \mathrm{~h} 30$ e seleção aleatória por intervalo de tempo com manifestantes acima de 15 anos. A margem de erro foi de 4,2 pontos percentuais; pesquisa nacional realizada pelo Ibope nas manifestações do dia 20 com 2002 entrevistas em oito cidades: São Paulo, Rio de Janeiro, Belo Horizonte, Porto Alegre, Recife, Fortaleza, Salvador e Brasília. As entrevistas foram feitas com manifestantes acima de 14 anos e a margem de erro foi de dois pontos percentuais para mais e para menos. Consultada em < $<$ 1.globo.com $>$ em 22/09/2013; pesquisa feita em Belo Horizonte na manifestação do dia 22, pelo Instituto Innovare, com 409 entrevistas de cinco minutos e margem de erro de cinco pontos percentuais para mais ou para menos. Consultada em <www. innovarepesquisa.com.br> em 22/09/2013. Agradeço a Antônio David por me alertar para a pesquisa do Ibope, assim como aos institutos Plus Marketing e Innovare pelo envio dos respectivos relatórios.
Tabela 2

Renda familiar mensal dos manifestantes

\begin{tabular}{|c|c|c|c|}
\hline Faixas & $\begin{array}{c}\text { Rio de Janeiro } \\
20 / 06\end{array}$ & $\begin{array}{c}\text { Oito capitais } \\
20 / 06\end{array}$ & $\begin{array}{c}\text { Belo } \\
\text { Horizonte } \\
22 / 06\end{array}$ \\
\hline Mais baixa & $\begin{array}{c}34 \% \\
\text { (Ate } 1 \mathrm{SM})\end{array}$ & $\begin{array}{c}15 \% \\
\text { (Até } 2 \mathrm{SM} \text { ) }\end{array}$ & $\begin{array}{c}20 \% \\
\text { (Até } 2 \mathrm{SM} \text { ) }\end{array}$ \\
\hline $\begin{array}{l}\text { Inter- } \\
\text { mediária } 1\end{array}$ & $\begin{array}{c}54 \% \\
\text { (De } 2 \text { a } 5 \text { SM) }\end{array}$ & $\begin{array}{c}30 \% \\
\text { (De } 2 \text { a } 5 \text { SM) }\end{array}$ & $\begin{array}{c}36 \% \\
(2 \text { a } 5 \mathrm{SM})\end{array}$ \\
\hline $\begin{array}{l}\text { Inter- } \\
\text { mediária } 2\end{array}$ & $\begin{array}{c}1 \% \\
(\text { De } 6 \text { a } 10 \mathrm{SM})\end{array}$ & $\begin{array}{c}26 \% \\
\text { (De } 5 \text { a } 10 \\
\text { SM) }\end{array}$ & $\begin{array}{c}24 \% \\
(5 \text { a } 10 \mathrm{SM})\end{array}$ \\
\hline Alta & $\begin{array}{c}10 \% \\
\text { (Mais de } 11 \\
\text { SM) }\end{array}$ & $\begin{array}{c}23 \% \\
\text { (Mais } 10 \mathrm{SM} \text { ) }\end{array}$ & $\begin{array}{c}21 \% \\
\text { (Mais de } 10 \\
\text { SM) }\end{array}$ \\
\hline & $100 \%$ & $100 \%$ & $100 \%$ \\
\hline
\end{tabular}

Fonte: Para o Rio de Janeiro, Plus Marketing. Para oito capitais, Ibope. Para Belo Horizonte, Innovare. $* 6 \%$ não responderam

Ao que parece, estamos em face de um contingente de jovens com renda baixa, mas escolaridade média ou até alta. Esses manifestantes se encontrariam dentro da faixa na qual o economista Waldir Quadros (2010) inclui ocupações como balconista, professor de ensino fundamental, auxiliar de enfermagem, auxiliar de escritório, recepcionista, motorista, garçom, barbeiro, cabeleireiro e manicure. ${ }^{13}$ A classificação pela renda familiar não nos permite saber a renda per capita do manifestante, mas, ao dizer que $45 \%$ dos participantes em oito capitais e $56 \%$ em Belo Horizonte não tinham renda familiar acima de cinco salários mínimos, o Ibope e o Innovare estão nos indicando que boa parte deles podia ter uma das profissões descritas por Quadros, não pertencendo, pois, à classe média tradicional, que se caracteriza por abrigar profissionais liberais ou funções não manuais, técnicas e administrativas, como especificam Souza e Lamounier (2010). As ocupações acima arroladas por Quadros estariam dentro da categoria "médio-inferior" estabelecida por Souza e Lamounier, ou seja, na metade de baixo da estratificação por ocupações.

Se considerarmos que a maioria dos manifestantes era jovem, tendo entrado recentemente no emprego - significativamente, o Ibope mostrou que $76 \%$ dos manifestantes estava no mercado de trabalho nas oito capitais, a Innovare encontrou proporção parecida em Belo Horizonte (71\%) e a Plus Marketing no Rio de Janeiro (70\%) -, a hipótese de uma presença do novo proletariado nas manifestações torna-se plausível. ${ }^{14}$

13 Para chegar a esse resultado, fiz uma conversão, em salários mínimos da época, da classificação apresentada por Waldir Quadros (2010).

14 Embora o dado deva ser visto com cuidado, pelas razões já mencionadas, cabe mencionar que a Plus Marketing encontrou $88 \%$ dos manifestantes do Rio na faixa de até cinco salários mínimos. 
Foram, portanto, em seu conjunto, protestos de jovens e jovens adultos de alta escolaridade. Mas, como tem assinalado o sociólogo Gustavo Venturi (2010), em função "do processo relativamente acentuado de escolarização ao longo da última década e meia" (p. 204), é razoável pensar que o novo proletariado tenha nível escolar elevado. Em função disso, deve-se cogitar a possibilidade de ter estado presente nas manifestações uma parcela de jovens de escolaridade mais alta que a renda, que é, aliás, a caracterização do operador de telemarketing, que tende a ter pelo menos escolaridade média completa, e às vezes universitária, com salário médio abaixo de 1,5 SM. Convém registrar que com a ampliação das vagas nas universidades públicas, com o Prouni e com a explosão do ensino superior privado, a quantidade de ingressantes nas universidades pulou de 1 para 2,3 milhões por ano entre 2001 e 2011 (Weber, 2012).

Se é verdade que para trabalhadores de baixa renda ainda está posta uma agenda materialista, deve-se considerar que esquerda e direita têm respostas para ela: mais Estado, de um lado, e mais mercado, de outro. Um novo centro, por sua vez, tenta escapar do dilema por meio do recurso à "maior participação social", proposta da qual, em tese, ninguém discorda, mas que colocada fora do conflito distributivo só interessa a quem já está com seus problemas materiais resolvidos.

No entanto, é possível que, embora materialmente distante, o universo da classe média tradicional, que oscila entre a direita e o centro, seja alvo do desejo de jovens que começam a se mover naquela direção por meio da elevação educacional. Ensina a sociologia que, quando não existem fortes subculturas de classe em ação, os indivíduos podem desenvolver identificações com o lugar social para o qual querem ir e não com o terreno de onde vêm.

Cabe lembrar que esse novo proletariado nasceu em um ambiente cultural com forte carga capitalista. Em primeiro lugar, houve a expansão da chamada teologia da prosperidade, que envolve uma série de igrejas pentecostais e neopentecostais. Essa visão de mundo propõe que o esforço individual de cada um o fará conseguir a ascensão social e o sucesso almejados. Em segundo lugar, a profunda impregnação que a sociedade vem sofrendo há algumas décadas do neoliberalismo tem como resultado, por exemplo, a adoração das marcas que vem se espalhando pela juventude das periferias das metrópoles brasileiras. A adoração das marcas é algo que combina muito bem com a teologia da prosperidade, ambas remetendo a valores capitalistas.

Segundo o Ibope, na noite de 20 de junho de 2013, quando levadas em consideração as três principais reivindicações espontaneamente levantadas pelos manifestantes entrevistados, a mudança do ambiente político ficou em primeiro lugar, tendo sido mencionada por $65 \%$ dos presentes, com $50 \%$ fazendo referência especificamente à corrupção, bandeira adotada como prioritária pela direita e pelo centro nas manifestações a partir de 17 de junho. Bandeiras de esquerda, como a questão do transporte, ficaram em segundo lugar, com $54 \%$ das respostas; os gastos com a Copa vieram em terceiro, com $40 \%$. Seria interessante pesquisar, no futuro, se houve alguma associação entre essas opções, a escolaridade e a renda dos entrevistados.

Com as evidências atuais não é possível afirmar para que lado pendeu o novo proletariado. Tanto pode ter tido uma compreensão de que os problemas postos só poderão ser resolvidos com gastos sociais por parte do Estado, como pensa a esquerda, quanto uma adesão à noção contrária, defendida pela direita, de que só o combate à corrupção pode levar a uma maior produção de riqueza. Assim como é plausível ter havido uma simpatia pela ideia de que a solução dos problemas sociais brasileiros passa por maior participação social e uma redução do Estado, como quer o centro pós-materialista.

O que percebemos é que, no auge das manifestações, as diversas correntes ideológicas estavam presentes na rua (Tabela 3). Apesar da expulsão simbólica da esquerda partidária da avenida Paulista na noite da quinta, 20 de junho, onde tudo havia começado duas semanas antes, a esquerda social lá permaneceu, representando uma parcela significativa (22\%), embora não majoritária, do protesto. Da mesma maneira, havia uma direita que, contudo, era bem menor (10\%) do que fizeram pensar as primeiras impressões a respeito do acontecido. O centro, por sua vez, predominava do ponto de vista numérico (31\%, no mínimo, e $66 \%$, no máximo, se somados a centro-esquerda e a centro-direita). Nada impede que o novo proletariado tenha se dividido entre essas orientações, o que futuras pesquisas poderão esclarecer.

Tabela 3

Localização dos manifestantes no espectro ideológico

\begin{tabular}{cccccc}
\hline Esquerda & $\begin{array}{c}\text { Centro- } \\
\text {-esquerda }\end{array}$ & $\begin{array}{c}\text { Centro } \\
\text { - }\end{array}$ & $\begin{array}{c}\text { Centro- } \\
\text {-direita }\end{array}$ & Direita & $\begin{array}{c}\text { Não } \\
\text { sabe }\end{array}$ \\
\hline $22 \%$ & $14 \%$ & $31 \%$ & $11 \%$ & $10 \%$ & $13 \%$ \\
\hline Fonte: Datafolha & & & & &
\end{tabular}

\section{Nota 3. Pequena nova classe média}

O economista Marcelo Neri (2010) sustenta que a classe $\mathrm{C}$, uma categorização que vem das pesquisas de mercado e é feita a partir de faixas de renda e de consumo, incorpora cerca de $50 \%$ da população brasileira, como se pode ver na Tabela 4. Por isso, a classe média teria se tornado majoritária no país. Ocorre que a classe $\mathrm{C}$, que prefiro chamar de faixa $\mathrm{C}$ para não criar confusão sociológica, não é a classe média no sentido tradicional, que se poderia caracterizar como está no livro dos cientistas políticos Bolivar Lamounier e Amaury de Souza (2010), aquela que está estabelecida como tal há pelo menos uma geração, ou seja, que já tem acesso a determinados bens e serviços desde os pais. 
Tabela 4

Estratificação da população brasileira em faixas de renda, 2009*

\begin{tabular}{cc}
\hline Faixas A e B & $10 \%$ \\
Faixa C & $50 \%$ \\
Faixas D e E & $40 \%$ \\
\hline
\end{tabular}

Fonte: Neri (2010). Reelaborado pelo autor. *Números aproximados, para dar uma ordem de grandezas

Quais são os bens e serviços que caracterizam esse padrão de vida da classe média tradicional no Brasil? Sem pretender uma resposta rigorosa, talvez se pudesse pensar no acesso aos planos de saúde e às escolas particulares para o ensino fundamental e médio (já que no ensino superior, o setor público ainda é considerado melhor).

Do ponto de vista numérico, a classe média tradicional coincide com o que as pesquisas de mercado assimilam como faixas A e B, por volta de $10 \%$ da população (ver Tabela 4). Do ângulo eleitoral, isso é um problema para a oposição que, enquanto estiver isolada nesse estrato, tem poucas chances de ganhar a eleição presidencial. Daí o seu desafio ser o de quebrar tal barreira. O sociólogo Jessé de Sousa tem razão quando assinala que interessa à oposição chamar os grupos emergentes de classe média, porque ao fazê-lo ajuda a criar neles uma identidade e um elo com a classe média tradicional, que tende a ser oposicionista.

Apesar disso, talvez devêssemos considerar a hipótese de que exista, dentro da faixa $\mathrm{C}$, um grupo relativamente pequeno que deu um salto maior e que está, de fato, se aproximando da faixa B, com acesso a planos de saúde privados e a escolas particulares, por exemplo. Nesse caso, fiando-me em informações fragmentárias, como relatos de campanhas políticas, filmes e descrições de pesquisa de campo, seria possível pensar em indivíduos que, vindos de um meio subproletário, conseguiram uma melhora superior à retratada na imagem do operador de telemarketing. Esses casos, relativamente excepcionais, começariam a ter aspirações de classe média, como aparece no filme Família Braz - Dois tempos, de Arthur Fontes e Dorrit Harazim, de 2010, deixando para trás a identificação com o universo popular. A experiência histórica mostra que em processos de ascensão individual pode haver uma ruptura rápida com a base da qual se proveio, em troca de uma identificação com o lugar para o qual se quer ir.

Como vimos, na Tabela 1 há uma vasta parcela (21\%) que o DIEESE chama de trabalhadores por conta própria. Uma parte pequena deles deve ser não o trabalhador que vive de bicos, o típico membro do setor informal, mas indivíduos que estão tentando mudar de vida por meio de atividades ou negócios autônomos, fugindo e/ou sendo excluídos do assalariamento. Aí o empreendedorismo estaria associado à pequena camada que se aproxima de padrões de classe média.
Esse cidadão é candidato a uma ideologia hipercapitalista, porque em sua experiência o esforço pessoal, portanto o mérito, ocupa lugar central, ao passo que os direitos coletivos pouco representam. Além disso, ele é um atual ou futuro empregador, portanto está virtual ou realmente do outro lado do balcão da relação capital-trabalho. Da mesma maneira como o novo proletariado tem condições materiais de existência que combinam com uma posição de esquerda, a pequena nova classe média teria interesses objetivos ao centro e à direita, sendo muito sensível à ideia de que o Estado atrapalha. É possível, por exemplo, que uma parte dos estudantes do Prouni compartilhe de tais pontos de vista. Se assim for, eles teriam chegado à universidade por meio de uma política governamental voltada à inclusão, mas podem preferir que o governo se afaste da economia e diminua os impostos, mesmo que ao custo de cortar programas sociais, para que pequenos empreendedores possam ter mais sucesso.

Assim como as que se referem ao novo proletariado, a hipótese sobre a pequena nova classe média merece ser pesquisada, para que surjam elementos quantitativos e qualitativos capazes de precisar o que está de fato acontecendo.

\section{Nota 4. Mudança nas coalizões de classe}

A reativação do mercado interno por baixo, realizada nos dois governos Lula, junto com a manutenção de linhas macroeconômicas neoliberais, parecia ter estabilizado, ao final do segundo mandato do ex-presidente, duas coalizões de classe contrapostas. De um lado, uma coalizão produtivista, reunindo facções da burguesia e da classe trabalhadora organizada, ambas supostamente interessadas em aumentar a produção e o consumo internos. De outro, uma coalizão rentista, reunindo a facção financeira do capital e a classe média tradicional, as duas voltadas para altos ganhos financeiros, em uma perspectiva de divisão internacional do trabalho na qual o Brasil se concentraria em exportar commodities, importando os produtos de alto valor agregado que não seria capaz de produzir. Dividida, por sua vez, entre o interesse de ter um real desvalorizado e, ao mesmo tempo, manter fluidas as vias de comércio exterior com um mercado nacional aberto às importações, a burguesia agroexportadora estaria associada a uma e outra das coalizões acima referidas, oscilando entre ambas (A. Singer, 2012). ${ }^{15}$

Em um contexto de expansão mundial, Lula foi capaz de equilibrar o peso das coalizões, fazendo concessões ora a uma ora a outra, sem confrontar interesses essenciais. Sustentado por uma fração específica de classe - o subproletariado -, o lulismo teria logrado avançar o combate à pobreza sem radicalização política, não por acaso o programa dos setores mais vulneráveis e excluídos da própria participação na luta de classes sobre os quais se apoiou.

Em maio de 2011, com a assinatura de um protocolo entre as principais centrais sindicais (CUT e Força

15 Ver, especialmente, os capítulos 3 e 4. 
Sindical) e a mais poderosa federação industrial do país (Fiesp), a coalizão produtivista se formalizou. Redução da taxa de juros, desvalorização cambial, investimento produtivo e manutenção do emprego foram o programa firmado por trabalhadores e empresários. No horizonte estava a perspectiva de reindustrialização, permitindo haver crescimento com distribuição de renda.

Algumas semanas depois desse protocolo ser formalizado, o Banco Central iniciou uma expressiva redução da taxa Selic, envolvendo, na sequência, vigorosa pressão do Ministério da Fazenda para a diminuição dos spreads praticados pelos bancos privados. Alguns meses mais tarde (fevereiro de 2012), o governo procederia a uma desvalorização cambial, estendendo, de maneira significativa, o raio de ação do Estado em benefício dos produtores nacionais. Na mesma linha, em maio de 2012, Dilma promulgou uma delicada mudança nas regras de remuneração da caderneta de poupança, de modo a permitir que a redução da taxa de juros prosseguisse além do que nunca havia ido desde o início do lulismo. Para completar, no final de 2012, interveio no setor elétrico, reorganizando contratos e obrigando uma redução das tarifas de energia.

Tudo leva a crer que, na conjuntura de prolongada retração mundial que se reabriu em meados de 2011, a presidente entendeu ser necessário dar os passos para garantir a continuidade do crescimento econômico e combate à desigualdade. Em consequência, entre meados de 2011 e meados de 2012, houve no Brasil um verdadeiro ensaio desenvolvimentista. Ao enfrentar o capital financeiro que, pela primeira vez desde o início do lulismo, havia perdido o controle do Banco Central, o governo tentou romper com os limites impostos anteriormente e, assim, dar continuidade ao projeto lulista.

Com a área econômica do governo unificada (Fazenda e Banco Central), Dilma orientou no sentido da expressiva queda da taxa de juros, pressionando o setor financeiro a adotar conduta voltada para estimular a produção e não o rentismo. Assim, foram alterados dois dos três mandamentos da economia política neoliberal - as metas de inflação e o câmbio flutuante -, sendo que o terceiro pilar, o superávit primário, já tinha de algum modo sido flexibilizado no período anterior. Em outras palavras, as linhas de política macroeconômica saíram do padrão neoliberal.
O problema é saber por que o ensaio desenvolvimentista fracassou. O crescimento econômico de 2012 ( $0,9 \%$ do PIB) mostra que embora corajosas, as iniciativas governamentais foram ineficazes para alcançar o objetivo principal (retomada do crescimento com distribuição da renda), levando o governo a suspender a orientação produtivista, retomando a política de juros altos e câmbio livre, além de promover privatizações em diversos setores e desonerar os empresários de recolher o devido à Previdência Social sobre a folha de pagamentos. Aparentemente, e para usar expressão que ouvi em debate recente, "a burguesia faltou outra vez ao encontro", como o fizera antes de 1964, não realizando os investimentos esperados pelo governo e, com isso, causando a queda do ritmo de crescimento.

Se o lado burguês da coalizão rentista (coalizão produtivista?) decepcionou, a reação da coalizão rentista às medidas desenvolvimentistas foi o esperado. Instaurouse uma verdadeira guerra contra o "intervencionismo na economia". Aparentemente, a ofensiva teve o condão não apenas de pressionar o governo a voltar atrás, mas também de dividir a coalizão produtivista, atraindo o capital produtivo para a órbita da coalizão rentista. À medida que o capital produtivo se afastava da coalizão inicial, iniciando uma série de manifestações contra o "intervencionismo", o governo, isolado da burguesia, suspendia o ensaio desenvolvimentista. Em abril de 2013, os juros voltaram a subir, ameaçando a perspectiva de crescimento pelo terceiro ano consecutivo, os controles sobre o capital especulativo estrangeiro foram suspensos e uma postura privatizante foi adotada em setores estratégicos.

O maior sinal de que a coalizão produtivista se desfez é o reposicionamento dos empresários em relação aos trabalhadores, sobressaindo a posição de que o crescimento da economia dependeria agora de uma redução do custo da mão de obra, como fica claro no documento da Confederação Nacional da Indústria ("101 propostas para modernização trabalhista") divulgado em dezembro de 2012. Até o momento em que estas notas eram finalizadas (novembro 2013), a formação de um bloco burguês reunificado contra a candidatura Dilma Roussef em 2014 parecia o elemento distintivo em relação ao arranjo de classe da experiência lulista anterior.

\title{
Four notes on social classes in the ten years of Lulism
}

\begin{abstract}
The article intends to contribute to setting forth a hypothesis to explain some of the changes in the structure of social classes during the Lulism decade (2003-2013). The enhancement in living conditions for approximately 40 million Brazilians led to a reconfiguration in several points of the society, all the way from alleviating the survival conditions of the sub-proletariat, to the upsurge of a small new middle class, going through the emergence of a vast new sub-proletariat, a variety of transformations particularly attained the popular layers of society. The article seeks to present initial interpretations regarding these diverse phenomena.
\end{abstract}

Keywords: classes, lulism, social ascension. 


\section{Quatre notes au sujet des classes sociales pendant les dix ans de Lulisme}

Rèsumè: L'intention de cet article est de contribuer à la formulation d'hypothèses explicatives à l'égard des changements dans la structure de classes survenus tout au long de la décennie Luliste (2003-2013). L'amélioration des conditions de vie d'environ 40 millions de Brésiliens a entraîné une reconfiguration de divers points de la société. Du soulagement de la condition de survie à l'avènement d'une petite nouvelle classe moyenne, en passant par l'émergence d'un vaste sous-prolétariat, une variété de transformations a atteint, notamment, les couches populaires. L'article vise à présenter des interprétations initiales à propos de ces divers phénomènes.

Mots-clés: classes, Lulisme, ascension sociale.

\section{Cuatro notas sobre las clases sociales en los diez años del lulismo}

Resumen: El artículo pretende aportar una hipótesis que explique algunos de los cambios en la estructura social que ocurrieron durante la década lulista (2003-2013). La mejoría en las condiciones de vida por parte de algo como 40 millones de brasileños significo una reconfiguración en varios puntos de la sociedad. Desde aliviar la condición de supervivencia del subproletariado, hasta la emergencia de una pequeña nueva clase media, pasando por el surgimiento de un amplio nuevo proletariado. Enfin, una diversidad de transformaciones impactó especialmente a los estratos populares. El artículo intenta presentar interpretaciones iniciales sobre estos distintos fenómenos.

Palabras clave: clases, lulismo, ascensión social.

\section{Referências}

Antunes, R., \& Braga, R.(2009). Infoproletários. Degradação real do trabalho virtual. São Paulo, SP: Boitempo.

Braga, R. (2013). Sob a sombra do precariado. In E. Maricato, Cidades rebeldes (pp. 79-82). São Paulo, SP: Boitempo.

Neri, M. (2010). A nova classe média, o lado brilhante dos pobres. Rio de Janeiro, RJ: FGV.

Quadros, W. (2010, 01 de novembro). Brasil: um país de classe média? Le Monde Diplomatique Brasil, 4(40). Disponível em http://www.diplomatique.org.br/artigo. php?id $=803$

Singer, A. (2012). Os sentidos do lulismo. Reforma gradual e pacto conservador. São Paulo, SP: Companhia das Letras.

Singer, A. (2013). Brasil, junho de 2013: classes e ideologias cruzadas. Novos Estudos CEBRAP, 97, 23-40.

Singer, P. (1981). Dominação e desigualdade. Estrutura de classes e repartição de renda no Brasil. Rio de Janeiro, RJ: Paz e Terra.
Soares, S. S. D. (2010). O ritmo na queda da desigualdade no Brasil é aceitável? Revista de Economia Política, 30(3), 369-370.

Souza, A., \& Lamounier, B. (2010). A classe média brasileira: ambições, valores e projetos de sociedade. Rio de Janeiro, RJ: Elsevier.

Venturi, G. (2010). PT 30 anos: crescimento e mudanças na preferência partidária. Perseu, 4(5), 197-214.

Weber, D. (2012, 17 de outubro). Brasil tem 6,7 milhões de universitários. O Globo. Disponível em http://oglobo. globo.com/sociedade/educacao/brasil-tem-67-milhoesde-universitarios-6423216 